\author{
Military Technical College \\ Kobry Elkobbah, \\ Cairo, Egypt
}

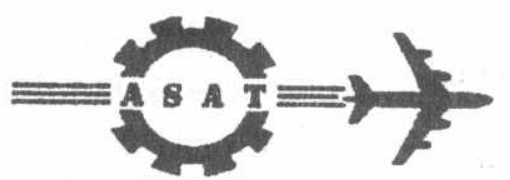

$8^{\text {th }}$ International Conference on Aerospace Sciences \& Aviation Technology

\title{
AGE HARDENING CHARACTERISTICS AND MECHANICAL PROPERTIES OF ALUMINUM ALLOY 2024
}

\author{
H. M. Kandil
}

\begin{abstract}
The age hardening behavior of the commercial 2024 aluminum alloy was the interest of the present investigation. The mechanical properties of alloys in the two temper conditions; T6 and T86, were susceptible to the aging processes. Artificial aging at different temperatures appreciably improved both hardness and tensile properties of the present alloy, however, at the ductility. Strain introduced by stretching prior to the precipitation hardening process further increased the hardness and tensile parameters. This alloy is characterized by a high ratio of yield to tensile strength. In the T6-temper condition, a maximum tensile strength of $482 \mathrm{MPa}$ and a yield strength of $444 \mathrm{MPa}$ were attained after $12 \mathrm{~h}$ aging at $190^{\circ} \mathrm{C}$. In addition, the alloy in the T86-temper condition attained even higher tensile strength of $506 \mathrm{MPa}$ and a yield of $467 \mathrm{MPa}$ after aging only for $6 \mathrm{~h}$ at the same aging temperature. The initial age hardening was found to be a diffusion-controlled process with an activation energy of $0.83 \pm 0.01 \mathrm{eV}$ for the T6-temper and $0.90 \pm 0.01 \mathrm{eV}$ for the T86-temper. The present precipitation hardening treatments have, however, a deleterious effect on both ductility and notch toughness.
\end{abstract}

\section{KEY WORDS}

Aluminum Alloy 2024, Age Hardening, Mechanical Properties.

\section{INTRODUCTION}

Aluminum alloy 2024 (AA 2024) is characterized by high specific strength, good fracture toughness, and excellent fatigue properties This alloy, particularly in the T8-type temper, is well suited for the industry of supersonic and military aircraft.

The microstructure of AA 2024 is characterized by the complex nature of second phase particles. In aluminum-containing copper alloys precipitation was reported [1] to start with the spherical Guinier-Preston (GP) zones. In Al-Cu-Mg alloys the strengthening precipitates, in addition to GP zones, are mainly the $S^{\prime}$ and $S$ phase $\left(A L_{2} \mathrm{CuMg}\right)$ [2]. The morphology and growth modes of these dispersion precipitates

Mechanical Engineering Department, Faculty of Engineering, Zagazig University, Benha Branch, Cairo, Egypt 
during aging are responsible for the alloy strength. Shin et al. [2] reported that optimum properties are achieved in AA 2024 by changing solute content, adding impurity elements, and thermo-mechanical pre-aging treatment. These authors found that the nucleation rate of $S^{\prime}$ phase is more strongly stimulated by applying preaging strain than by increasing alloying contents. Other workers $[3,4]$ reported that mechanical pretreatment introduces high dislocation density into the structure and hence increases alloy strength. Mechanical pretreatment was also found [5] to improve the high-temperature flow behavior of AA 2024 by hot rolling followed by press forging then heat treating.

\section{EXPERIMENTAL}

A cast commercial AA 2024 (60 kg charge/metallic mold) was homogenized in a muffle furnace at $480 \pm 2^{\circ} \mathrm{C}$ for $24 \mathrm{~h}$. Cylindrical and square bars were extruded at $450^{\circ} \mathrm{C}$, annealed at $450^{\circ} \mathrm{C}$ for $4-6 \mathrm{~h}$, and then hot- and cold-drawn down in two-step reduction of $0.5 \mathrm{~mm}$ each and cut to the required dimensions. The drawn specimens as well as the machined $v$-notch specimens were annealed again at $450^{\circ} \mathrm{C}$ for $1 \mathrm{~h}$. After solid-solution treatment at $495^{\circ} \mathrm{C}$ for $1 \mathrm{~h}$ and quenching into room-temperature water, some of the test specimens were immediately stretched to $6 \%$ at room temperature. These stretched specimens are denoted T86 ones while others are denoted T6 specimens. Artificial aging was conducted at four different. temperatures; $170,190,210$, and $230^{\circ} \mathrm{C}$. The maximum duration at room temperature between solid solution and artificial aging was <15 minutes, during which the effect of natural aging, as reported by Shin et al. [2], is not significant. The composition of the alloy studied was determined using the Spectro Analytical Instruments analyzer, German made. This composition (in weight pct) is $4.13 \mathrm{Cu}$, $1.45 \mathrm{Mg}, 0.31 \mathrm{Si}, 0.15 \mathrm{Fe}, 0.61 \mathrm{Mn}, 0.21 \mathrm{Zn}, 0.015 \mathrm{Cr}, 0.015 \mathrm{Ti}$, and balance Al.

The mechanical properties were assessed through hardness, tensile and $v$-notch Charpy tests. Brinell hardness measurements were carried out on the ESEWAY hardness tester, UK made. The hardness value (BHN) was the average of at least 12 measurements taken uniformly over the polished sample surface. Tension test was carried out on shouldered-end specimens of $5 \mathrm{~mm}$-diameter and $25 \mathrm{~mm}$-gage length using the Monsanto Tensometer 2000 machine, UK r.lade. The precision in hardness and strength measuremen's is $\pm 1 \%$, and $\pm 5 \%$ in the impact energy measurement. The V-notch Charpy test was done onl! at room temperature on $1 \times 1 \mathrm{~cm}$ square and $6 \mathrm{~cm}$ long bars using a German made Ansler impact tester.

\section{RESULTS AND DISCUSSION}

\section{Age Hardening Characteristics}

The artificial aging response of AA 2024 investigated at four different temperatures is plotted for T6 and T86 tempers, respectively, in Fig. 1(a and b). This alloy shows a typical age hardening behavior where hardness increases with aging time until it reaches maximum and then decreases with over aging. Peak hardness is attained earlier as aging temperature is increased. The T6 peak hardness values at 170, 190,210 , and $230^{\circ} \mathrm{C}$ are reached, respectively, after $24,12,5$, and $0.5 \mathrm{~h}$ of aging. 
Ine 186 specimens showed higher values of peak hardness attained at even shorter aging times; $14,6,1$, and $0.3 \mathrm{~h}$, at the same corresponding aging temperatures. In the present study, the kinetics of the precipitation hardening process is accelerated and peak hardness is reached earlier with increasing aging temperature and with introducing mechanical pre-aging treatment. This behavior may be explained by the microstructure developed during aging and the TEM investigation [2] done on similar alloy. The amount of the strengthening precipitates $S^{\prime}$ rapidly increases with increasing aging time until peak hardness is reached. The density and volume fraction of these precipitates are higher in the cold worked specimens than those in the T6 specimens. Further aging would result in a microstructure of widely spaced and incoherent coarse precipitates leading to a decrease in alloy hardness. The peak hardness, in the present study, was found to gradually decrease due to relative softening with increasing aging temperature. A maximum peak hardness of 177 $\mathrm{BHN}$ is attained at $190^{\circ} \mathrm{C} / 6 \mathrm{~h}$ for $\mathrm{AA} 2024-\mathrm{T} 86$. In contrast, the as-quenched hardness values of the T6 and T86 tempers are, respectively, 95 and 107 BHN.

\section{Kinetics of Aging}

The kinetics of precipitation and dissolution of metastable and stable phases could best be described by 3-D volume diffusion process [6] in many age-hardenable aluminum alloys. Accordingly, the isothermal aging curves of Fig.1 ( $a$ and $b$ ), at four different temperatures; $170,190,210$, and $230^{\circ} \mathrm{C}$, were used to determine the activation energy associated with the early stage of hardening according to the following Arrhenius relation.

$$
t=t_{0} \exp (E / k T)
$$

where $t$ is the time, in minutes, to reach a specified hardness ; taken as $142 \mathrm{BHN}$ and $161 \mathrm{BHN}$, respectively, for T6 and T86 tempers, and other terms have their usual meanings. Using a least squares analysis, two linear plots of In t versus $(1 / T)$ were obtained for the T6 and T86 alloys, as shown in Fig. 2 ( $a$ and b). From these limited results it appears that the early stage of hardening is a diffusion-controlled process. The activation energy of the two tempers, T6 and T86, are then determined, respectively, as $0.83 \pm 0.01 \mathrm{eV}$ and $0.90 \pm 0.01 \mathrm{eV}$.

\section{Tensile Properties}

Fig. 3 shows the effect of age hardening behavior of the T6 and T86 tempers on the tensile parameters; (a) ultimate tensile strength (UTS), (b) yield strength (YS), and (c) pct total elongation. The pattern of these curves well correlates with that of age hardening curves of Fig. 1. Evidently, this is expected from the general relation between tensile strength and hardness of aluminum alloys [7]: Maximum strength of $482 \mathrm{MPa}$ is attained for AA2024-T6, while AA2024-T86 shows a higher strength of $506 \mathrm{MPa}$ at the same peak-aging condition $\left(190^{\circ} \mathrm{C} / 6 \mathrm{~h}\right)$. The general behavior of the variation of strength with aging time may be analogous to that described by hardness response. This is briefly described by a three-stage behavior; an initial 
increase with aging time, reaching maximum or peak aging, and then followed by a decrease with further aging. In addition, the effect of temperature on tensile properties is nearly the same at all temperatures studied $\left(170-230^{\circ} \mathrm{C}\right)$. This may be expected and interpreted in terms of the microstructure developed in this range of aging temperature. The ductility, on the other hand, shows a corresponding opposite behavior to strength and hardness with aging practice, as shown in Fig. 3(c). The present optimum strength parameters, in addition to the modulus of elasticity $(E)$, at peak-aged condition at $190^{\circ} \mathrm{C}$, are compared with similar results obtained by other workers $[8,9]$ in Table 1 .

Table 1. Comparison of optimum strength parameters of AA 2024-TB6.

\begin{tabular}{|c|c|c|c|c|}
\hline UTS (MPa) & YS (MPa) & $\%$ Tot: elong. & $E\{G P a\}$ & Reference \\
\hline 506 & 467 & 5.2 & 74 & present \\
\hline 530 & 400 & 13 & 72.8 & [8] \\
\hline 460 & 443 & 8 & 73.3 & [9] \\
\hline
\end{tabular}

\section{Notched Impact Energy}

The present results of Table 2 show the influence of the different aging temperatures on the notch toughness of peak-aged AA 2024-T86. Tensile strength of peak-aged condition at different aging temperatures is also given in the table. Unfortunately, the impact energy of this alloy increases at the expense of its strength. Therefore, further work has to be done to optimize the combination of strength-toughness propierty.

Table 2. Notched impact energy of peak-aged AA2024-T86

\begin{tabular}{|c|c|c|c|c|}
\hline Aging temperature $\left({ }^{\circ} \mathrm{C}\right)$ & 170 & 190 & 210 & 230 \\
\hline Energy absorbed $\left(3 / \mathrm{cm}^{2}\right)$ & 7.82 & 6.34 & 9.14 & 13.83 \\
\hline Tensile strength (MPa) & 494 & 506 & 485 & 475 \\
\hline
\end{tabular}

\section{CONCLUSIONS}

The mecharical properties of AA 2024 are appreciably affected by artificial aging as well as by the strain introduced by cold working (stretching) prior to the age hardening treatment. The results of hardness and tensile measurements were accounted for the following conclusions. 
1. Maximum hardness and strength are achieved for $A A$ 2024-T86 aged at $190^{\circ} \mathrm{C} / 6 \mathrm{~h}$.

2. Mechanical pretreatment accelerates initial aging kinetics and further improves both hardness and strength, however, at the expense of ductility.

3. The early stage of aging is a diffusion-controlled process. The activation energy of this process is determined for the two T6 and T86 tempers, respectively, as $0.83 \pm 0.01 \mathrm{eV}$ and $0.90 \pm 0.01 \mathrm{eV}$.

4. The AA 2024-T86 possesses a high ratio of yield to tensile strength.

5. Precipitation hardening treatment of AA 2024 has a deleterious effect on notch toughness.

\section{ACKNOWLEDGMENTS}

The author sincerely acknowledges the staff members of the Planning and Foundry Departments at Helwan Company for Nonferrous Industries, Egypt for providing the materials, with their chemical analysis, used in present investigation.

\section{REFERENCES}

[1] J. Noordhuis and J. Th .M. De Hosson, Microstructure and Mechanical Properties of a Laser Treated Al Alloy, Acta Metall. Mater., Vol. 41, No. 7, pp. 1989-1998, 1993

[2] Han-Cheng Shin, New-Jin Ho, and J. C. Huang, Precipitation Behaviors in Al$\mathrm{Cu}-\mathrm{Mg}$ and 2024 Aluminum Alloy, Metall.Mater. Trans. A, Vol. 27A, pp 24792494, September 1996

[3] Juarez-Islas, J.A., Perez, R., Lengsfeld, P., and Lavernia, E.J., Microstructural and Mechanical Evaluations of Spray-Deposited 7xxx Al-Alloys after Conventional Consolidation, Mater. Sci. and Eng., Vol. A179/A180, pp. 614-618, 1994

[4] Meininger, J.M., Dickerson, S.L., and Gibeling, J.C., Observation of TensionCompression Asymmetry in the Cyclic Deformation of Aluminum Alloy 7075, Fatigue Fract. Eng. Mater. Struct., Vol. 19, No. 1, pp. 85-97, 1996

[5] P. L. Charpentier, B. C. Stone, S.C. Ernst, and J. F. Thomas, Jr., Characterization and Modeling of the High Temperature Flow Behavior of Aluminum Alloy 2024, Metall. Trans. A, Vol. 17A, pp 2227-2237, 1986

[6] Papazian, J.M., Calorimetric Studies of Precipitation and Dissolution Kinetics in Aluminum Alloys 2219 and 7075, Metall. Trans. A, Vol. 13A, pp. 761-769, 1982

[7] ASM Metals Handbook, Heat Treating, $9^{\text {th }}$ ed., Vol. 4, ASM, Metals Park, Ohio, pp 675-718, 1981

[8] Joseph Baram, Structure and Properties of a Rapidly Solidified Al-Li-Mn-Zr Alloy for High-Temperature Applications: Part II. Spray Atomization and Deposition Processing, Metall. Trans. A, Vol. 22A, pp 2515-2522, October 1991

[9] H. F. Wu, Temperature Dependence of the Tensile Properties of ARAL-4 Laminates, J. Mater. Sci., Vol. 25, pp 1120-1127, 1990 

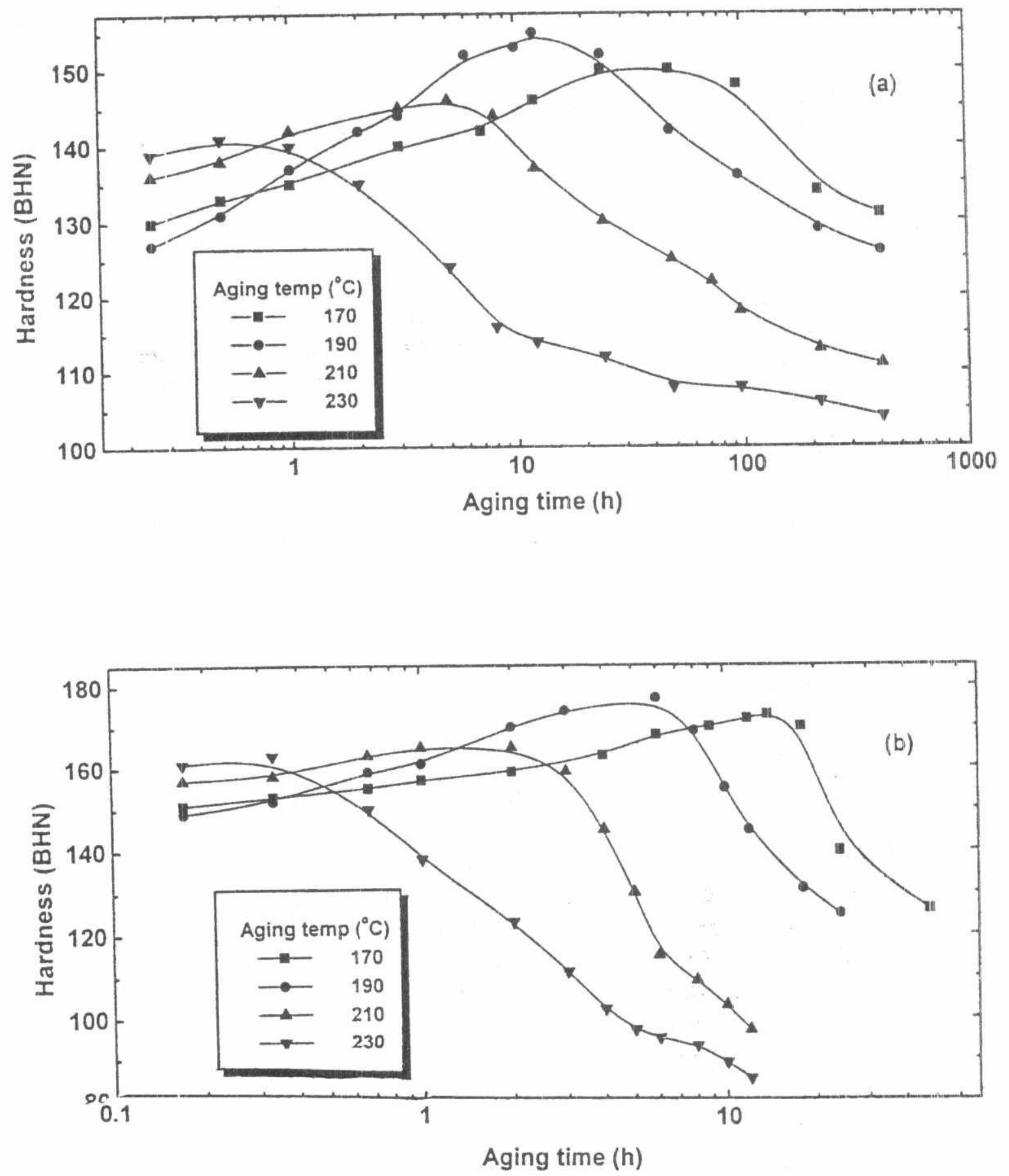

FIG. 1: VAFIIATION OF HARDNESS WITH AGING TIME AND TEMPERATURE IN AA 2024 AT TWO TEMPERS; (a) T6 AND (b) T86 

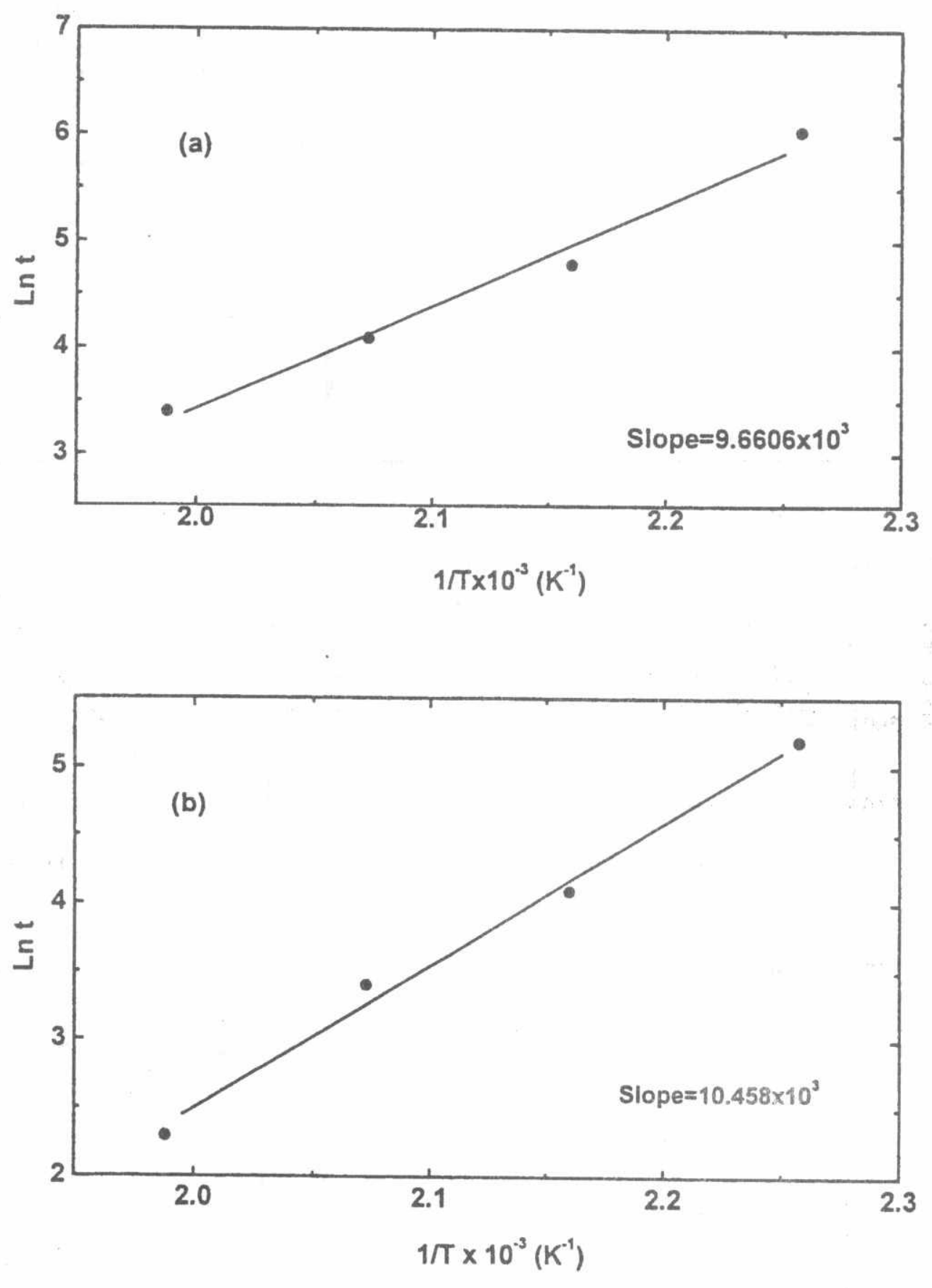

FIG. 2: ARRHENIUS PLOT OF Ln t VS 1/T FOR THE INITIAL AGING PROCESS IN AA 2024 AT TWO TEMPERS, (a) T6 AND (b) T86 

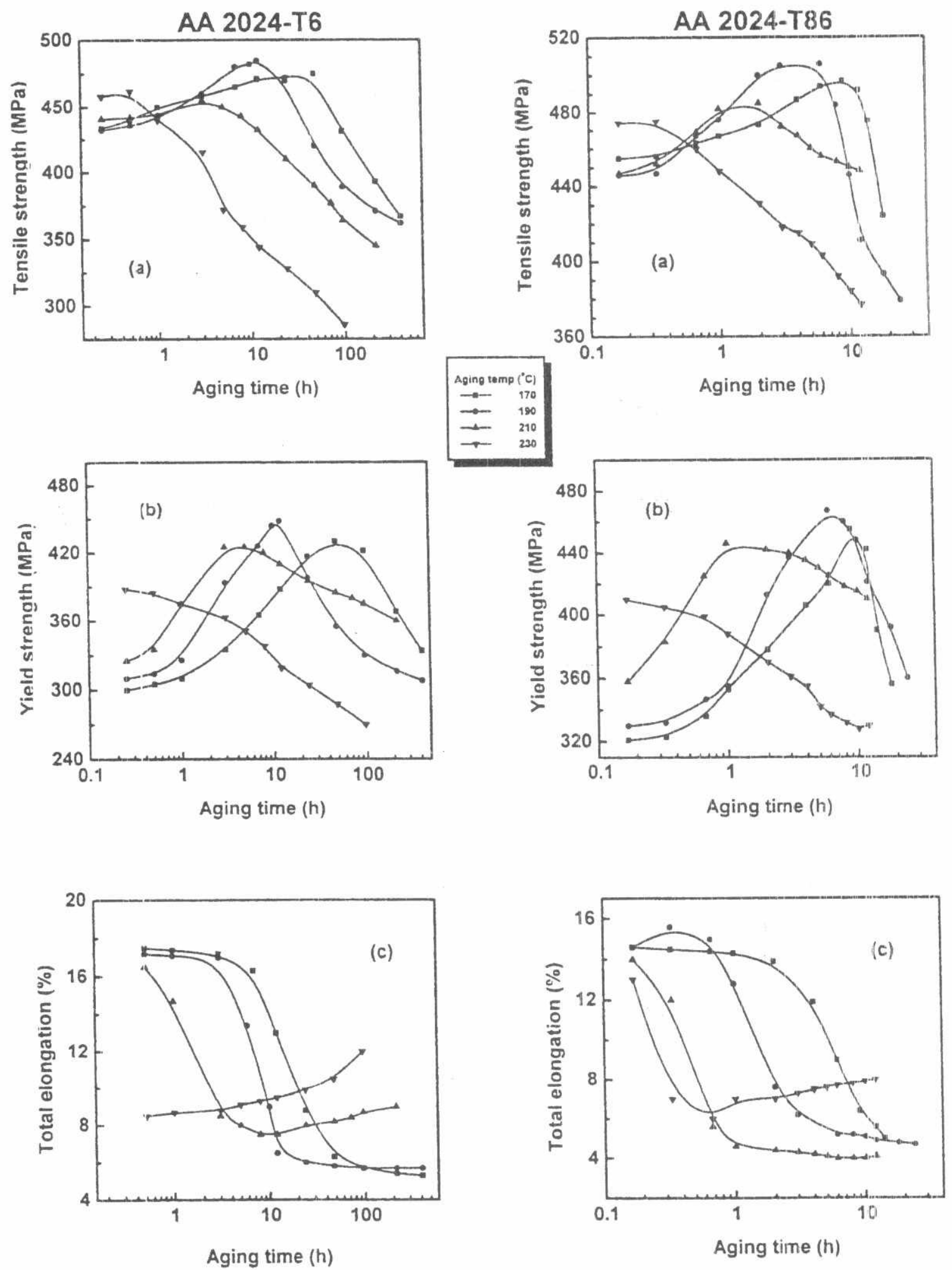

FIG. 3: EFFECT OF AGING TIME AND TEMPERATURE ON TENSILE PROPERTIES OF AA 2024-T6 AND AA 2024-T86; (a) TENSILE STRENGTH, (b) YIELD STRENGTH, AND (c) \% ELONGATION 